\title{
Tensile-dominant fractures observed in hydraulic fracturing laboratory experiment using eagle ford shale
}

\section{$\operatorname{AUTHOR}(\mathrm{S})$ :}

Naoi, Makoto; Chen, Youqing; Yamamoto, Kazune; Morishige, Yuya; Imakita, Keiichi; Tsutumi, Naofumi; Kawakata, Hironori; ... Arima, Yutaro; Kitamura, Shigehiro; Hyodo, Daisuke

\section{CITATION:}

Naoi, Makoto ... [et al]. Tensile-dominant fractures observed in hydraulic fracturing laboratory experiment using eagle ford shale. Geophysical Journal International 2020, 222(2): $769-780$

\section{ISSUE DATE:}

2020-8-1

URL:

http://hdl.handle.net/2433/252463

\section{RIGHT:}

This article has been accepted for publication in 'Geophysical Journal International' (c) The Author(s) 2020. Published by Oxford University Press on behalf of The Royal Astronomical Society. All rights reserved. 


\title{
Tensile-dominant fractures observed in hydraulic fracturing laboratory experiment using eagle ford shale
}

\author{
Makoto Naoi, ${ }^{1}$ Youqing Chen, ${ }^{2}$ Kazune Yamamoto, ${ }^{3}$ Yuya Morishige, ${ }^{2}$ Keiichi Imakita, ${ }^{3}$ \\ Naofumi Tsutumi, ${ }^{2}$ Hironori Kawakata, ${ }^{4}$ Tsuyoshi Ishida, ${ }^{3}$ Hiroyuki Tanaka, ${ }^{5}$ \\ Yutaro Arima, ${ }^{5}$ Shigehiro Kitamura ${ }^{5}$ and Daisuke Hyodo ${ }^{5}$ \\ ${ }^{1}$ Research Center for Earthquake Prediction, Disaster Prevention Research Institute, Kyoto University, Gokasyo, Uji, Kyoto 611-0011, Japan. E-mail: \\ naoi.makoto.4z@kyoto-u.ac.jp \\ ${ }^{2}$ Department of Energy Science and Technology, Graduate School of Energy Science, Kyoto University, Yoshida-Honmachi, Sakyo-ku, Kyoto 606-8501, Japan \\ ${ }^{3}$ Department of Civil and Earth Resources Engineering, Graduate School of Engineering, Kyoto University, Kyoto Daigaku Katsura Cluster-C, Nishikyo-ku, \\ Kyoto, 615-8540, Japan \\ ${ }^{4}$ College of Science and Engineering, Ritsumeikan University, 1-1-1 Noji Higashi, Kusatsu, 525-8577, Japan \\ ${ }^{5}$ Japan Oil, Gas and Metals National Corporation, 1-2-2 Hamada, Mihama-ku, Chiba-city, Chiba, 261-0025, Japan
}

\section{SUMMAR Y}

Hydraulic fracturing plays a vital role in the development of unconventional energy resources, such as shale gas/oil and enhanced geothermal systems to increase the permeability of tight rocks. In this study, we conducted hydraulic fracturing experiments in a laboratory using carbonate-rich outcrop samples of Eagle Ford shale from the United States. We used a thermosetting acrylic resin containing a fluorescent compound as a fracturing fluid. Immediately after fracturing, the liquid resin penetrated in the fractured blocks was hardened by applying heat. Then, the crack was viewed under UV irradiation, where the fluorescent resin allowed the induced fracture to be clearly observed, indicating the formation of simple, thin bi-wing planar fractures. We observed the detailed structure of the fractures from microscopy of thin cross-sections, and found that their complexity and width varied with the distance from the wellbore. This likely reflects the change in the stress state around the tip of the growing fracture. The interaction between fractures and constituent grains/other inclusions (e.g. organic substances) seemed to increase the complexity of the fractures, which may contribute to the efficient production of shale gas/oil via hydraulic fracturing. We first detected acoustic emission (AE) signals several seconds before the peak fluid pressure was observed, and the active region gradually migrated along the microscopically observed fracture with increasing magnitude. Immediately after the peak pressure was observed, the fluid pressure dropped suddenly (breakdown) with large seismic waves that were probably radiated by dynamic propagation of the fracture; thereafter, the AE activity stopped. We applied moment tensor inversion for the obtained AE events by carefully correcting the AE sensor characteristics. Almost all of the solutions corresponded to tensile events that had a crack plane along the maximum compression axis, as would be expected based on the conventional theory of hydraulic fracturing. Such domination of tensile events has not been reported in previous studies based on laboratory/in situ experiments, where shear events were often dominant. The extreme domination of the tensile events in the present study is possibly a result of the use of rock samples without any significant pre-existing cracks. Our experiments revealed the fracturing behaviour and accompanying seismic activities of very tight rocks in detail, which will be helpful to our understanding of fracturing behaviour in shale gas/oil resource production.

Key words: Fracture and flow; Earthquake source observations; Induced seismicity; Fractures, faults, and high strain deformation zones. 


\section{INTRODUCTION}

In the development of shale gas/oil resources, hydraulic fracturing is used to increase the fluid paths in a tight, low-permeability shale layer. Although microseismic (MS) observation can evaluate the influence region of fracturing (e.g. Maxwell 2014), it is not clear whether all MS events contribute to resource development. During actual resource development, proppants (small particles of sand or ceramic) are injected to prevent the closure of induced cracks to maintain the high permeability of the rock layer after fracturing. Thus, tensile openings, which are expected to be induced by the stress state around a wellbore (e.g. Hubbert \& Willis 1957; Yew \& Weng 2014), are necessary to accommodate the proppant in the actual production (Maxwell \& Cipolla 2011). However, MS activities observed in actual production fields are often dominated by shear events (e.g. Maxwell \& Cipolla 2011; Ś́lený et al. 2014; Staněk \& Eisner 2017), and it is unknown whether such shear events significantly contribute to resource extraction. In addition, some studies have reported the possibility that the seismic moment is partly released aseismically during fluid injection (Hallo et al. 2014; Cornet 2016; McGarr \& Barbour 2018). Further studies are required to achieve a better understanding of the relationship between induced fractures and MS.

We recently conducted hydraulic fracturing experiments in a laboratory, where direct observation of induced fractures and measurement of very small seismic events, called acoustic-emission (AE) events, was possible (Akai et al. 2015; Chen et al. 2018; Naoi et al. 2018; Yamamoto et al. 2019). In our experimental method, a thermosetting acrylic resin containing a fluorescent compound was used as the fracturing fluid. The resin penetrated the rock samples and was hardened by heating after the fracturing experiment. When cut samples and thin cross-sections are viewed under UV (UV) light, the fluorescent resin provides a high contrast between the fluid penetration region, including the induced fractures, and the surrounding rock. Microscopic observation of the thin cross-sections allows us to analyse the induced fractures with an accuracy of a few microns. The observed structure of the fractures is compared with the $\mathrm{AE}$ activity. This relationship on a laboratory scale can be used to imply a relationship between MS events and the fractures induced in resource production fields.

The abovementioned experimental method revealed that the conditions of the rock significantly influence the fracture propagation process and accompanying AE activity. Naoi et al. (2018) used this method for laboratory-scale hydraulic fracturing experiments with blocks of Inai shale and Kurokami-Jima granite. The observed features of the fluid penetration region, AE activities, and fluid pressure histories of these two specimens differed significantly. Yamamoto et al. (2019) applied seismic moment tensor analysis to the AE events obtained for granite samples by carefully correcting the AE sensor characteristics, thereby revealing the occurrence of all shear, tensile, and compressive events. They also showed that the dominance of tensile events increased when the main direction of pre-existing cracks was almost perpendicular to the fracture propagation direction. The proportion of tensile events decreased when the dominant direction of pre-existing cracks was parallel to the fracture propagation direction. This indicates that the dominant mode of seismic events is significantly influenced by the interaction between the induced fractures and pre-existing cracks. Chen et al. (2018) observed the detailed microstructure of induced fractures via laboratory-scale hydraulic fracturing experiments with several shale samples; the complexity of the fractures was found to be affected by the distribution of pre-existing cracks and the constituent minerals.
Table 1. Physical properties of the Eagle Ford sample used in this study. Permeability and tensile strength were measured in the direction perpendicular to the sedimentary plane. The porosity and permeability were measured using a CMS-300 (Core Laboratories) at $5.5 \mathrm{MPa}(800 \mathrm{psi})$ and $14 \mathrm{MPa}$ (2000 psi) pressure. Unmeasurable for many samples due to extremely low values.

\begin{tabular}{lc}
\hline Bulk density & $2600 \mathrm{~kg} \mathrm{~m}^{-3}$ \\
Porosity & $\leq 1 \mathrm{per}$ cent \\
Permeability & $\leq 10^{-4} \mathrm{mD}$ \\
Uniaxial compression strength & $100 \mathrm{MPa}$ \\
Static Young's modulus & $50 \mathrm{GPa}$ \\
Static Poisson ratio & 0.33 \\
Tensile strength & $2-9 \mathrm{MPa}$ \\
\hline
\end{tabular}

Previous studies demonstrated that the rock type greatly affects the properties of the induced fractures and corresponding AE activity measured during laboratory experiments. Hence, to allow laboratory data and findings to be applied to actual production scenarios, it is essential to use samples of the geological layers targeted in resource production operations. In this study, we used samples of Eagle Ford shale, which plays a vital role in development of shale gas/oil in the USA, for the laboratory fracturing experiments. We measured the AE signals during the experiments and applied moment tensor analysis to these data to investigate the fracture mode. We used the method described earlier for visualizing the fluid penetration region, including the induced fractures.

\section{EXPERIMENTAL SETTINGS}

\subsection{Sample}

In our fracturing experiments, we used three blocks of Eagle Ford shale extracted from an outcrop in Langtry, Texas, USA. Table 1 lists the physical properties measured for representative samples collected from the same site. The elastic wave velocities measured for the three rectangular blocks have been shown in Table 2. Although the sedimentary planes were evident on the surface of the samples, a significant degree of velocity anisotropy was not observed. X-ray diffraction (XRD) data showed that calcite was the dominant mineral ( 96.3 per cent), followed by quartz (3.7 per cent), which likely explains the low anisotropy in the velocities observed for these samples. Previous studies also reported that Eagle Ford shale has a calcite-rich formation (Anovitz et al. 2015). The tensile strength and permeability were measured in the directions perpendicular to the sedimentary plane, including the fracture propagation direction addressed in the present study (Section 3). As listed in Table 1, the obtained sample was significantly tight (lowpermeable), and other physical parameters were similar to those reported by previous studies (Cho et al. 2016).

Fig. 1 presents images of the samples obtained using polarizing microscopy. Several calcite particles with an oolitic shape, 50$200 \mu \mathrm{m}$ in diameter, were observed (Figs 1a and b). These particles, identified as microfossils of foraminifera (Romero et al. 2018), were in close contact with each other and were densely distributed. Almost all the remaining areas, except for calcite grains and the matrix (including clay minerals), could rarely be identified. Several inclusions (Figs 1c-e) were observed, which appear black under UV light irradiation (Fig. 1e). Such inclusions often appear as linear shapes on the section and lay parallel or subparallel to the sedimentary plane (Figs 1c-e). They are thought to arise from the inclusion of organic substances, such as a wood chips or leaves; hereafter referred to as 'organic inclusions'. 
Table 2. Experimental results and velocity of elastic waves for three samples of Eagle Ford shale.

\begin{tabular}{lcccccccccc}
\hline Sample & $\begin{array}{c}\text { Fluid injection } \\
\text { rate }\left[\mathrm{cc} \mathrm{min}{ }^{-1}\right]\end{array}$ & $\begin{array}{c}\text { Well-located } \\
\text { AE events* }\end{array}$ & $\begin{array}{c}\text { DD-relocated } \\
\text { AE events }\end{array}$ & $\begin{array}{c}\text { Breakdown } \\
\text { pressure }[\mathrm{MPa}]\end{array}$ & $\begin{array}{c}V_{\mathrm{P}}^{\mathrm{x}} \\
{\left[\mathrm{km} \mathrm{s}^{-1}\right]}\end{array}$ & $\begin{array}{c}V_{\mathrm{P}}^{\mathrm{y}} \\
{\left[\mathrm{km} \mathrm{s}^{-1}\right]}\end{array}$ & $\begin{array}{c}V_{\mathrm{P}}^{\mathrm{z}} \\
{\left[\mathrm{km} \mathrm{s}^{-1}\right]}\end{array}$ & $\begin{array}{c}V_{\mathrm{S}}^{\mathrm{x}} \\
{\left[\mathrm{km} \mathrm{s}^{-1}\right]}\end{array}$ & $\begin{array}{c}V_{\mathrm{S}}^{\mathrm{y}} \\
{\left[\mathrm{km} \mathrm{s}^{-1}\right]}\end{array}$ & $\begin{array}{c}V_{\mathrm{S}}^{\mathrm{z}} \\
{\left[\mathrm{km} \mathrm{s}^{-1}\right]}\end{array}$ \\
\hline EFS1701 & 1 & 497 & 482 & 11.79 & 6.19 & 6.05 & 6.14 & 3.22 & 3.19 \\
EFS1704 & 1 & 477 & 457 & 10.30 & 6.30 & 6.29 & 6.28 & 3.25 & 3.23 & 3.26 \\
EFS1706 & 1 & 534 & 504 & 10.71 & 6.29 & 6.32 & 6.29 & 3.24 & 3.24 & 3.28 \\
\hline
\end{tabular}

(a)

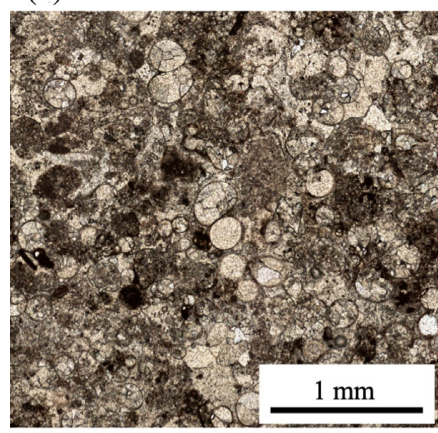

(c)

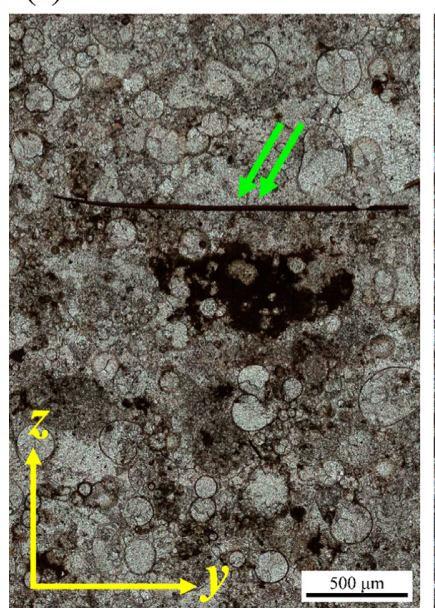

(b)

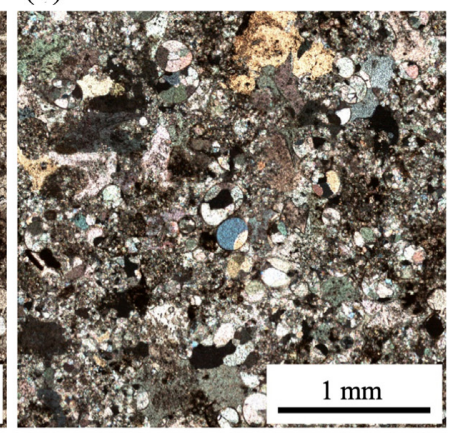

(d)

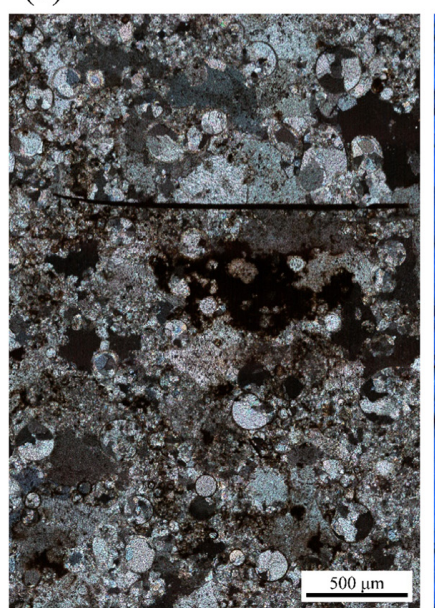

(e)

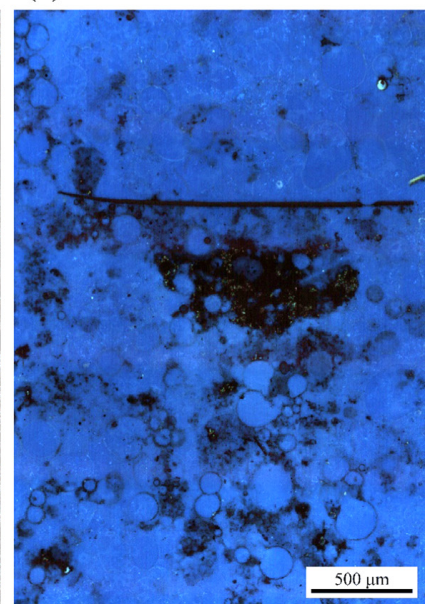

Figure 1. Microscopy images of Eagle Ford shale sample. Figures (a) and (b) are oolitic calcite particles. (a) Single Nicol, (b) crossed Nicols. (c)-(e) Micrographs of a linear inclusion attributed to an organic substance (green arrows in c) along the sedimentary plane ( $x-y$ plane). (c) Single Nicol, (d) crossed Nicols and (e) under UV light.

\subsection{Hydraulic fracturing experiments}

Fig. 2 shows schematic diagrams of the experimental setup used here, which is similar to that used by Naoi et al. (2018) and Yamamoto et al. (2019), with the exception of the sample size and AE sensor settings. We prepared three blocks (EFS1701, 1704 and 1706) with dimensions of $65 \times 65 \times 130 \mathrm{~mm}^{3}$, with the sedimentary plane parallel to the $x-y$ plane. The blocks had a wellbore with a diameter of $6 \mathrm{~mm}$ along the $x$-axis. We set a packer in the hole, which had a $30-\mathrm{mm}$ pressurising section sealed with two O-rings. We used a thermosetting acrylic resin, methyl methacrylate (MMA; viscosity of $0.80 \mathrm{mPa} s$ at room temperature) as the fracturing fluid. As shown in Fig. 2(a), it was injected into the packer using a cylindrical piston, and was pressurized by water injected from a syringe pump at a constant flow rate of $1 \mathrm{cc} \mathrm{min}^{-1}$. A pressure gauge was placed near the packer to measure the wellbore pressure, and its data were recorded continuously at a rate of $100 \mathrm{kS} \mathrm{s}^{-1}$ using a PXI-6251 (National Instruments Corp.) I/O module. All experiments were conducted under a loading of $5 \mathrm{MPa}$ along the $z$-axis.
We attached 16 broad-band AE transducers (M304A, Fuji Ceramics Corp.; diameter of $4 \mathrm{~mm}$ ), and $8 \mathrm{AE}$ transducers with a resonance frequency of $550 \mathrm{kHz}$ (PICO transducer; Physical Acoustic Corp.; diameter of $5 \mathrm{~mm}$ ) onto a block sample, as shown in Figs 2(b) and (c). The AE transducers on the top and bottom faces of the block were placed in small holes drilled into a loading board. The transducers were compressed using a spring to achieve pressures of approximately 1.5 and 1.3 MPa for the M304A and PICO transducers, respectively. The transducers on the side faces were attached using thermofusible wax, and had slightly lower sensitivities than those attached on the top and bottom faces. The signals from each transducer were continuously recorded at $10 \mathrm{MS} \mathrm{s}^{-1}$ using a 14-bit analogue-to-digital (A-D) converter (PXIe-5170R; National Instruments Corp.). The waveforms of the PICO sensors were recorded after the application of a $0.02-3 \mathrm{MHz}$ bandpass filter. Although we did not apply an analogue filter for the M304A sensors, highfrequency signals exceeding $2 \mathrm{MHz}$ are rarely observed due to their strong decay in rock samples. Hence, an anti-aliasing filter was not 
(a)

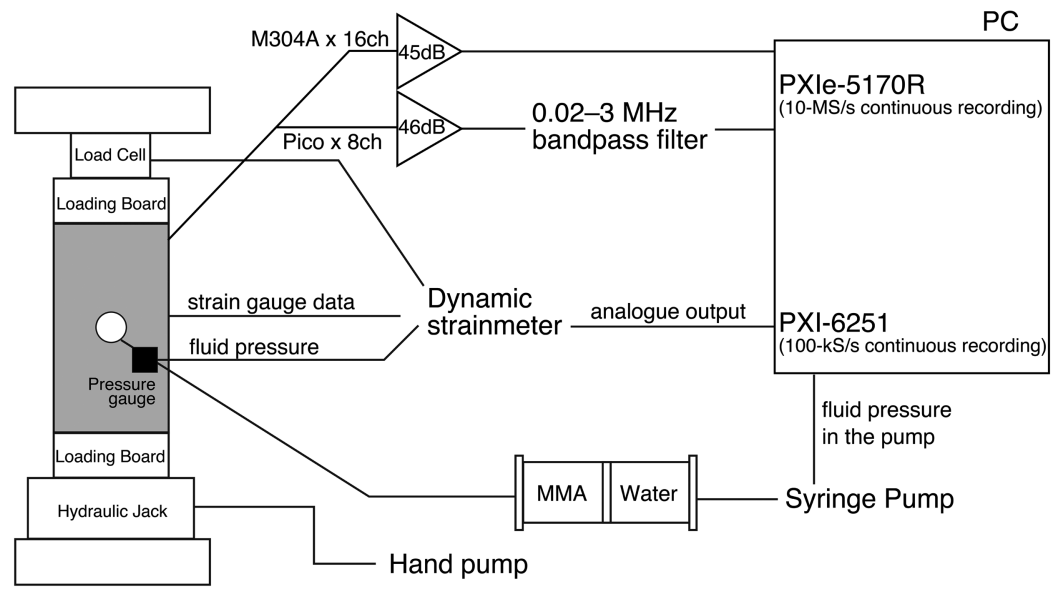

(b)

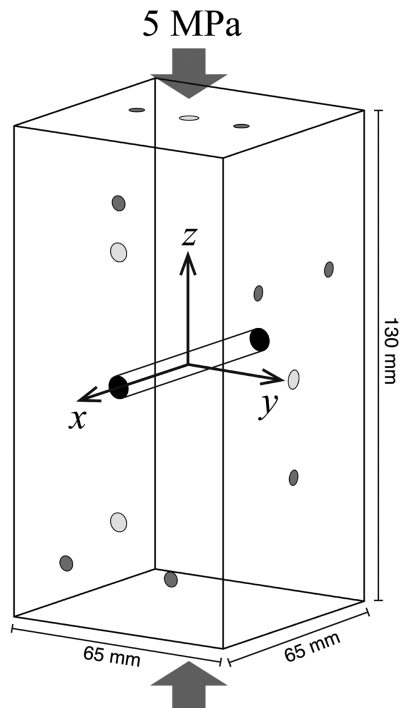

(c)

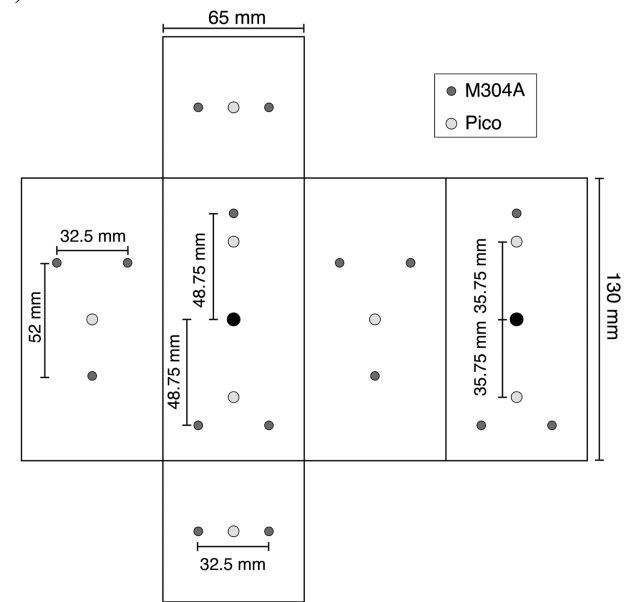

Figure 2. (a) Schematic diagram of experimental and data recording systems. (b) Schematic diagram defining the sample size, AE sensor position, and coordinate system used here. The origin of the coordinate system was the centre of the specimen. The black circle represents the wellbore. A packer was inserted along the $x$-axis from the positive side. Light and dark grey circles represent the positions of the PICO and M304A AE transducers, respectively (shown only on the front side for clarity). (c) AE sensor positions on the development projection.

necessary. The maximum amplitude of the A-D converter was $\pm 1 \mathrm{~V}$ for both sensors.

Incidentally, in previous studies (Naoi et al. 2018; Yamamoto et al. 2019), a physically larger, low-frequency transducer was used (R15, Physical Acoustic Corp.; resonance frequency of 75$150 \mathrm{kHz}$ ). The M304A used here has a comparable sensitivity, broader frequency response, and smaller size than the R15 as the preamp is incorporated in the sensor housing. The use of such a high-performance sensor enabled improved event detectability and accuracy in hypocentre determination. Although the sensitivity of the PICO transducer is less than that of the M304A transducer, it can radiate acoustic waves by applying voltage changes, which is necessary for the estimation of sensor sensitivity reflecting the coupling conditions in each experiment (Section 4.1).

\subsection{Cataloguing procedure of $\mathrm{AE}$ events}

We developed AE catalogues containing hypocentre coordinates and relative magnitudes based on waveforms that were continuously recorded during the experiments, using a procedure similar to that of Naoi et al. (2018). We applied an approach based on the ratio between short- and long-term average (STA/LTA) (Allen 1978) to identify AE events for the obtained waveforms, after applying a bandpass filter of 0.1-4 MHz. For each cut-out waveform, we automatically read the $P$-wave arrival times using the algorithm proposed by Takanami \& Kitagawa (1988). We estimated their hypocentres, event occurrence time, and location errors using a least-squares algorithm, considering $P$-wave anisotropy (Rothman et al. 1974). Only data from the M304A sensors were used, as these sensors are more sensitive than the PICO sensors. The $P$-wave velocity $\left(V_{P}\right)$ and $S$-wave velocity $\left(V_{S}\right)$ were measured along the $x$-, $y$ and $z$-axes prior to drilling the fracturing hole (Table 2). The arrival times that contained large residuals were eliminated during the iteration procedure for hypocentre determination (Naoi et al. 2018). We selected 'well-located events' from the results that satisfied the following conditions: (1) eight or more arrival times remained after the final iteration and (2) the location error $e_{\max }$, which is the maximum standard error among the three principal axes of an error ellipsoid, was less than $10 \mathrm{~mm}$. Subsequently, we relocated their hypocentres using the double-difference (DD) algorithm (Waldhauser \& 


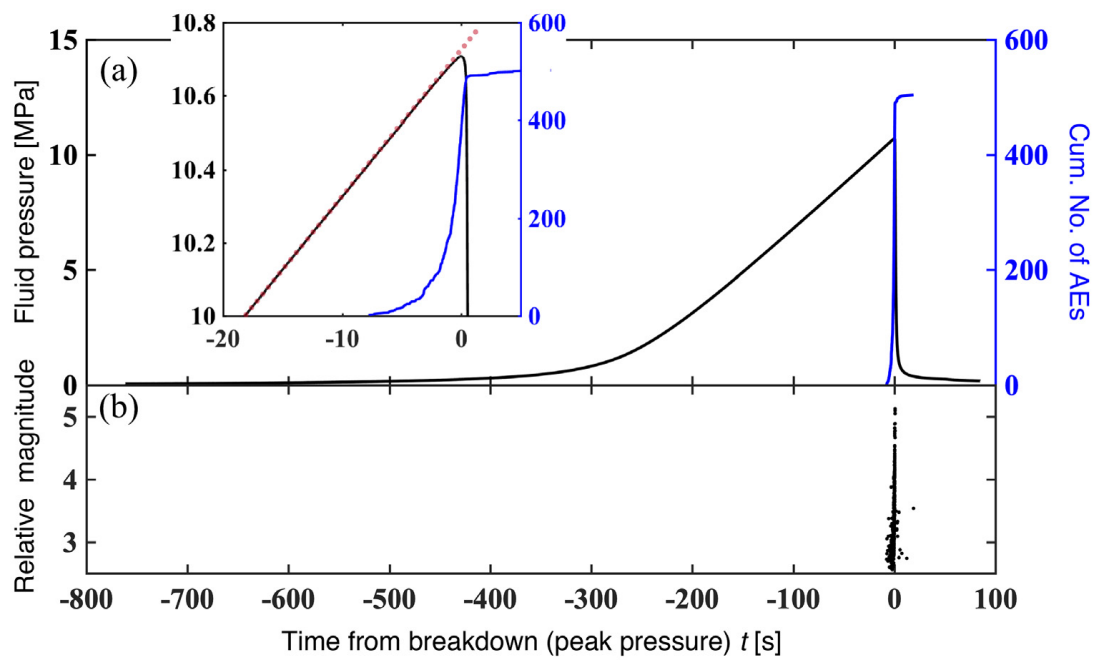

Figure 3. (a) Wellbore pressure history (black line) and the cumulative number of well-located AE events as a time from the peak pressure (blue line) for the experiment of EFS1706. Inset) Enlarged view around the breakdown point. The red dotted line is a linear approximation of the pressure increase. (b) Temporal change of relative magnitude of $\mathrm{AE}$ events.

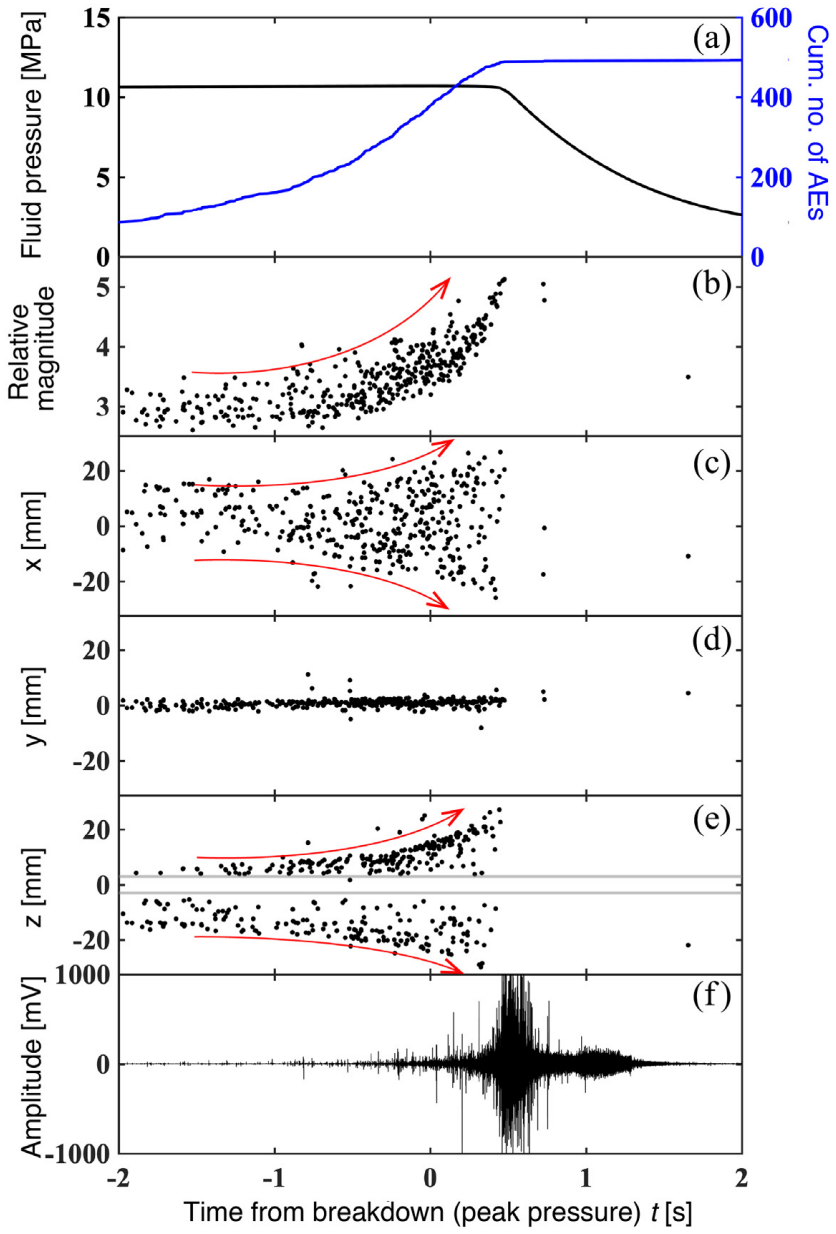

Figure 4. Wellbore pressure history and AE activity (DD results) around the breakdown $(-2 \mathrm{~s} \leq t \leq 2 \mathrm{~s})$ for sample EFS1706. (a) Cumulative number of $\mathrm{AE}$ events and fluid pressure history. (b) Change in relative magnitude. (c)-(e) Change in $x, y$ and $z$ coordinates of the hypocentres. (f) Continuous AE waveform recorded by an M304A sensor attached to the top face.
Ellsworth 2000). In this relocation process, we used arrival-time differences calculated from the automatic picking results, along with those measured using a waveform cross-correlation technique. The arrival-time data from the cross-correlation technique included the results based on waveforms recorded by the both the M304A and PICO sensors. For all three specimens, $\sim 95$ per cent of the total events were successfully relocated. Table 2 summarizes the number of located AE events.

Relative magnitudes $M$ for each event were estimated using the following equation:

$M=\frac{\Sigma \log _{10}\left(r_{i} \times A_{i}\right)}{N}$,

where $A_{i}$ is the waveform amplitude [mV] for the $i$ th AE sensor, $r_{i}$ is the distance [mm] between sensor $i$ and the hypocentre and $N$ is the number of sensors used for magnitude calculation. The amplitude $A_{i}$ was the peak-to-peak amplitude of each cut-out waveform. We only used data from 12 of the M304A sensors attached to the side faces of a block (i.e. we excluded all PICO sensors and the four M304A sensors attached in a different manner). Only signals with a signalto-noise ratio greater than 3 were used, and the saturated waveforms were not removed. The upper limit on the obtained magnitudes was approximately 5 .

\section{EXPERIMENTAL RESULTS}

\subsection{Fluid pressure history and AE activities}

The experiments for the three blocks showed good reproducibility. Hence, we only discuss the results for EFS1706 as a representative example. Fig. 3 shows the wellbore pressure history and cumulative number of well-located AE events as a function of elapsed time $t$, for which the origin is regarded as being the breakdown time (time at peak pressure). The fluid pressure reached a peak value of $10.7 \mathrm{MPa}$ at $t=0$ and then dropped rapidly (breakdown) to less than $1 \mathrm{MPa}$. The pressure increased linearly with time until approximately $2 \mathrm{~s}$ before the breakdown (Fig. 3a inset). Larger deviations from the linearly increasing trend have often been observed for laboratory hydraulic fracturing experiments using other rocks, such as granite 

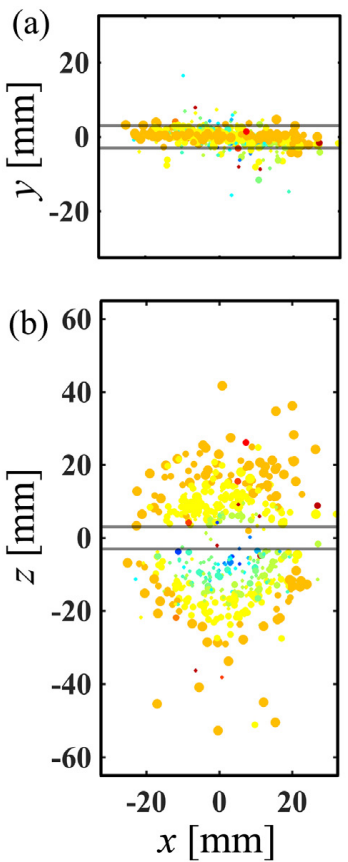

- $M \geq 4$

- $3 \leq \mathrm{M}<4$

$\cdot M<3$

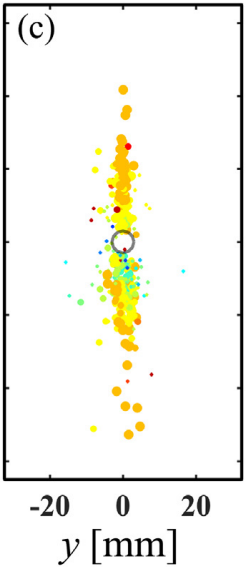

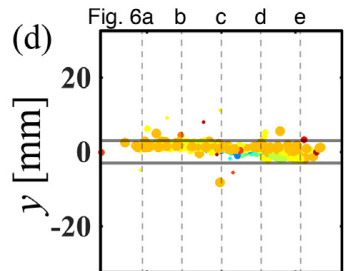

(e) 60

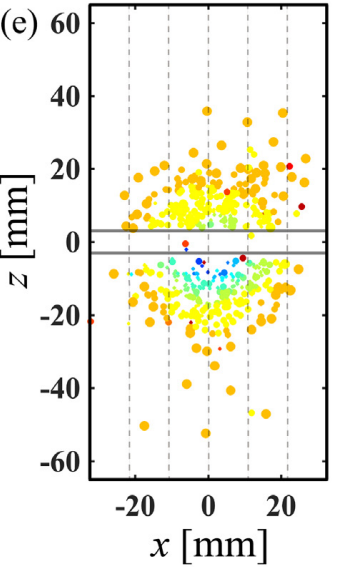

- $M \geq 4$

- $3 \leq \mathrm{M}<4$

- $M<3$

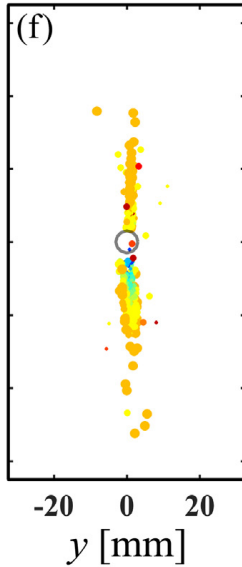

Figure 5. AE hypocentre distribution for EFS1706. The size of the circle represents the magnitude of the AE event. The colours represent the occurrence time of the event compared to the time of peak pressure. (a)-(c) Location results based on the method of Rothman et al. (1974) (only 504 events successfully relocated by the DD method are plotted). (d)-(f) Relocation results obtained using the DD algorithm. (a) and (d) Projection to the $x-y$ plane; (b) and (e) $x-z$ plane; and (c) and (f) $y-z$ plane.

(a)

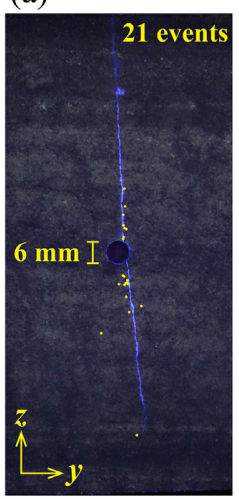

(b)

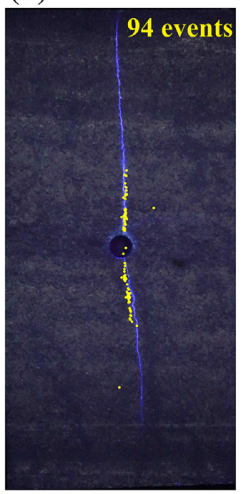

(c)

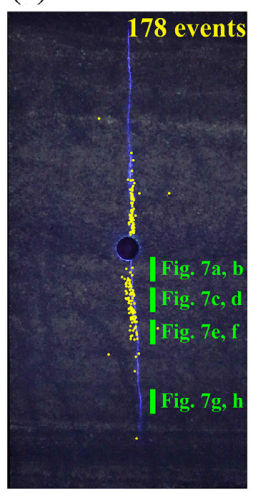

(d)

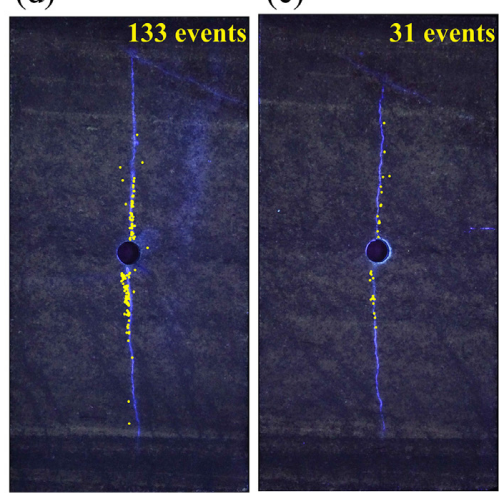

Figure 6. Resin penetration areas revealed by the fluorescent method on $y-z$ planes for EFS1706. Cross-section at (a) $x=-21.7 \mathrm{~mm}$, (b) $x=-10.8 \mathrm{~mm}$, (c) $x=0.0 \mathrm{~mm}$, (d) $x=+10.8 \mathrm{~mm}$ and (e) $x=+21.7 \mathrm{~mm}$. The bright and bluish-white parts represent the resin penetration region, including induced fractures. AE hypocentres (DD results) located within $5 \mathrm{~mm}$ from each plane are indicated by yellow dots. The black circle at centre of each image represents the wellbore (6-mm diameter).

(Naoi et al. 2018) and sandstone (Stanchits et al. 2014); this was attributed to the fracturing fluid entering the hydraulic fractures (Stanchits et al. 2014). Such deviations were rarely observed in this study, indicating that fluid penetration before breakdown was limited, as observed for Inai shale (Naoi et al. 2018).

The AE events started at $t \approx-8 \mathrm{~s}$, and their rate of occurrence increased until breakdown (Fig. 3a inset). Although the activity stopped after breakdown, the AE sensors detected large-amplitude waves for $\sim 1 \mathrm{~s}$ after the peak pressure was detected (Fig. 4f). This likely indicates that a seismic wave was radiated during fracture propagation. The amplitude of the recorded waveform decreased with time and settled to the noise level $1.3 \mathrm{~s}$ after breakdown. Thereafter, seismic signals were rarely detected.
Figs 5(a)-(c) show AE hypocentre distributions determined based on the method devised by Rothman et al. (1974), while Figs 5(d)-(f) show the values relocated using the double-difference (DD) method. Two-dimensional distributions parallel to the $x-z$ plane were observed for the results of both methods. The median of $e_{\max }$ for the automatically located hypocentres was about $1 \mathrm{~mm}$, and more accurate hypocentres were obtained after relocation, resulting in a very sharp, planar distribution.

The AE hypocentres accelerated from the wellbore toward the outside of the block with time until breakdown occurred (Figs 4c and e). The AE events were observed only in front of the active region until that time, where the active region expanded as concentric circles (Figs $5 \mathrm{~b}$ and e). The expansion of the active region likely corresponds to the growth of the hydraulic fractures, where $\mathrm{AE}$ 
(a)

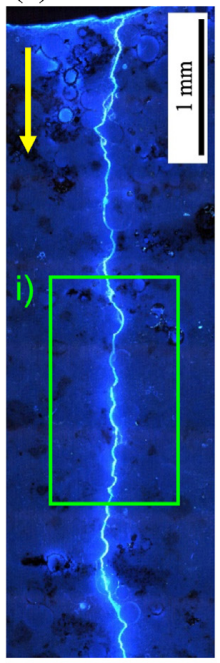

(i)

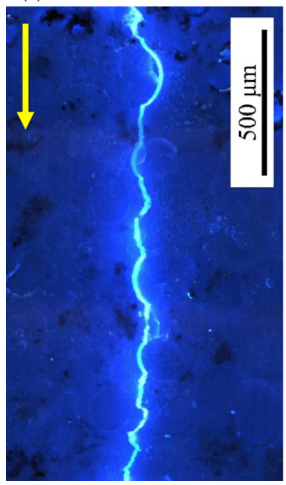

(b)

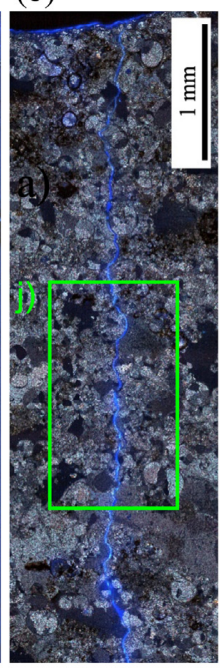

(c)

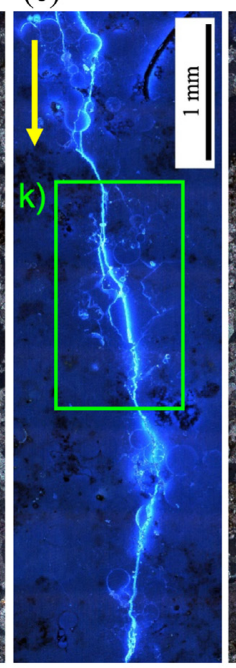

(d)

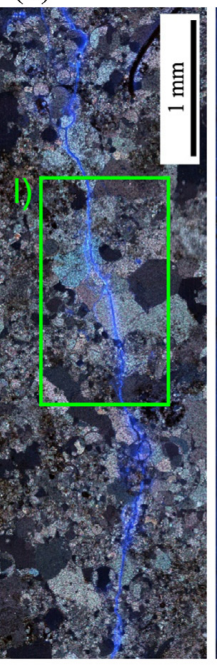

(e)

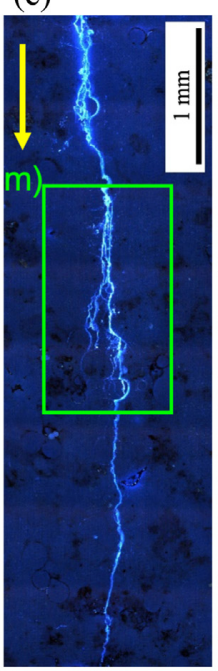

(f)

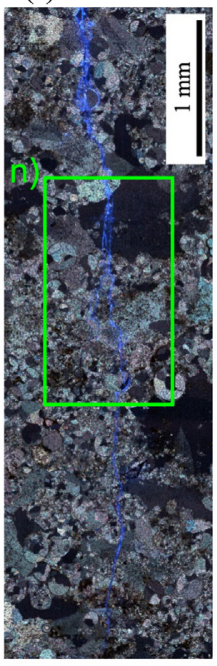

(m)

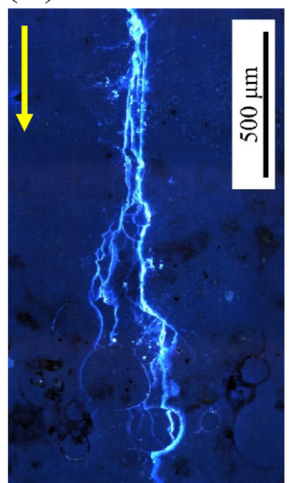

(g)

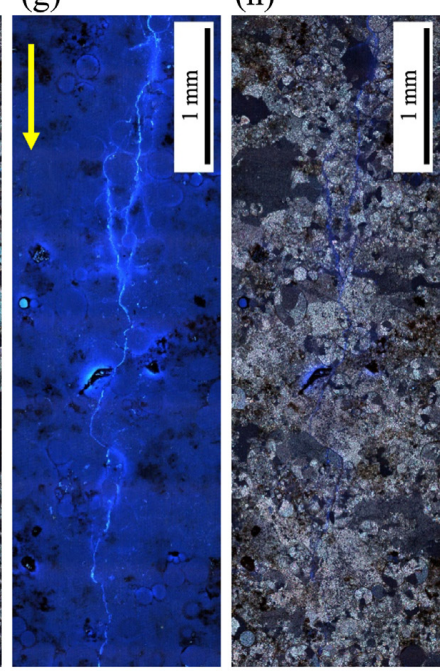

(j)

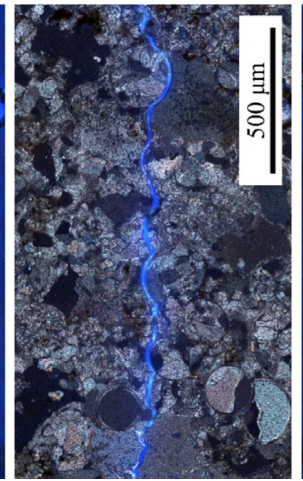

(k)

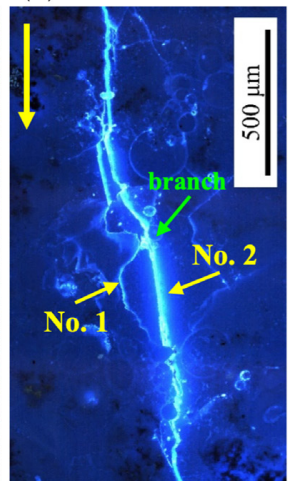

(1)

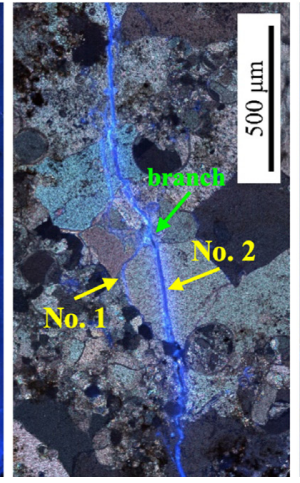

(n)

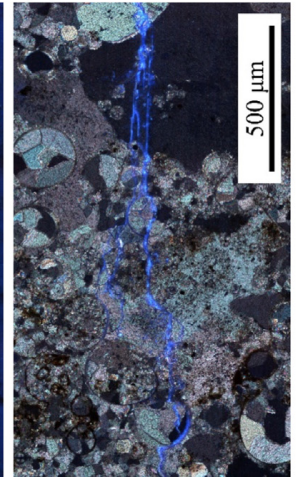

Figure 7. Microscopic observation of hydraulically induced fractures in EFS1706. (a)-(h) Each panel corresponds to the positions of the green lines in Fig. 6c (cut section at $x=0.0 \mathrm{~mm}$ ). (a, b) $z=-2.9$ to $-7.7 \mathrm{~mm}$; c, d) $z=-12.6$ to $-17.4 \mathrm{~mm}$; (e, f) $z=-21.5$ to $-26.3 \mathrm{~mm}$; and (g, h) $z=-40.7$ to $-45.5 \mathrm{~mm}$. (a), (c), (e), (g) under UV light, (b), (d), (f), (h) under crossed Nicols with UV light. Yellow arrows indicate the propagation direction of the induced fracture. (i)-(n) Enlarged views of the areas indicated by the green boxes in (a)-(f).

events occurred only around the edge of the induced fracture. The magnitude of the $\mathrm{AE}$ events increased at an increasing rate during fracture growth (Fig. 4b). The lower limits of the magnitude also increased with time, resulting from the increasing noise level.

\subsection{Macroscopic and microscopic structure of fluid penetration region}

After fracturing, we hardened the resin in the fractured blocks by heating in an oven maintained at $80^{\circ} \mathrm{C}$ or more for at least $12 \mathrm{hr}$ (Chen et al. 2018; Naoi et al. 2018). Subsequently, the block was sliced into six slabs parallel to the $y-z$ plane at positions of approximately $x=-21.7,-10.8,0.0,+10.8$ and $+21.7 \mathrm{~mm}$. Fig. 6 shows photographs of five sliced planes of EFS1706 taken under UV light with DD-relocated AE hypocentres within $5 \mathrm{~mm}$ of each plane. A pair of wing-like fractures was observed as thin luminous areas on each plane along the $z$-direction, showing the formation of the planar fracture parallel to the $x-z$ plane. The AE hypocentres delineated some parts of the observed fractures very well.

Fig. 6 shows that the induced fractures (luminous areas) reached close to the top of the block and stopped $\sim 10 \mathrm{~mm}$ from the bottom face. The AE hypocentres were determined in a $20-30 \mathrm{~mm}$ region from the wellbore, which is only part of the observed fracture and did not include the more distant region. As described in Section 3.1, AE accelerated along the $z$-axis from the wellbore, and seismic waves were radiated up to $\sim 1 \mathrm{~s}$ after AE events ceased. This indicates that the fracture initially propagated quasi-statically from the wellbore with accompanying $\mathrm{AE}$ events, and its growth rate increased with time, resulting in very fast dynamic fracture that radiated large-amplitude seismic waves. During the dynamic propagation, individual AE events were not identified probably because of saturated amplitude and long duration of the seismic wave. The shift to dynamic fracture propagation was likely a result of the crack size exceeding the critical size, as expected from the linear fracture mechanics (Griffith 1921; Irwin 1957).

To investigate the microscopic features of the induced fractures, we produced thin sections from the cut sections and observed them by polarizing microscope using two methods: (1) observation using only UV light by vertical illumination to identify the fluid penetration region and (2) polarising microscopy observation (with a single Nicol polarizer or crossed Nicols) using natural light and UV light to observe the rock textures and fluid penetration region, respectively, and the relationship between them. We observed that the fracture pattern changed with distance from the wellbore for all blocks. As an example, we describe the features along the $z$-direction for the central cut section of EFS1706. 


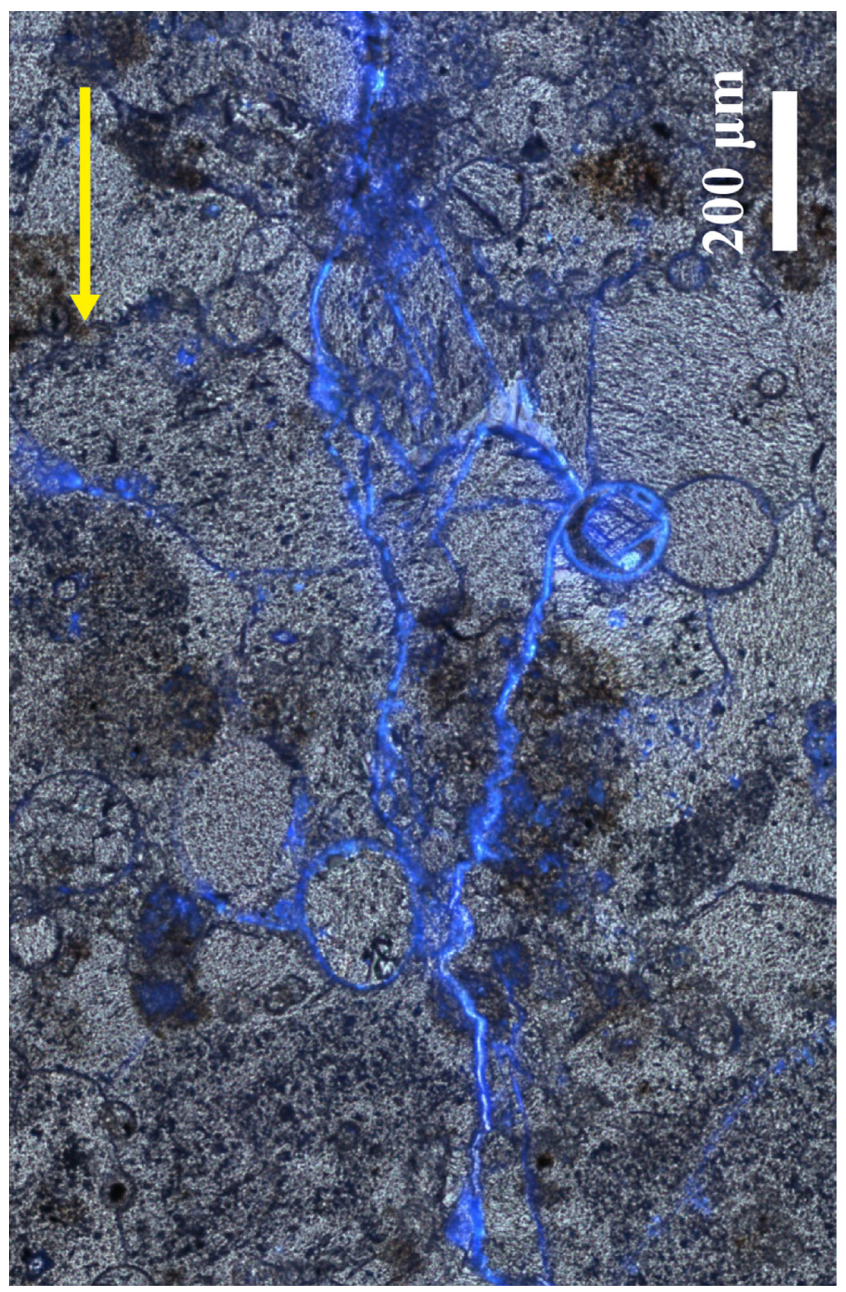

Figure 8. Example of the intricate fracture pattern between induced fractures and oolitic particles or calcite grains, under crossed Nicols with UV light (thin section from a slice of $x=-10.8 \mathrm{~mm}$ for EFS1701).

Figs 7(a)-(h) shows a series of micrographs of the thin sections at four different positions along the induced fracture corresponding to the green lines in Fig. 6(c). In the thin cross-sectional slices, induced fractures with a width of 1-20 $\mu \mathrm{m}$ can be clearly observed as the bright, bluish-white parts. Figs 7(a) and (b) shows those areas closest to the wellbore, where fractures without any branches were observed. Figs 7(i)-(n) shows higher-magnification images of the areas indicated by the green boxes in Figs 7(a)-(f), for the corresponding figure parts. In the regions shown in Figs 7(i) and (j), the fracture propagated through the boundaries of the oolitic grains without breaking them, resulting in grain-scale curvatures. In the region slightly removed from the wellbore (Figs 7c and d), the main fracture was also clearly observed. The grain-scale curvature was suppressed compared to that observed in Figs 7(i) and (j), probably due to the fracture breaking some grains, as shown in Figs 7(k) and (1). In this region, the fracture branched at a grain boundary, where fracture No. 1 propagated along the grain boundaries, while fracture No. 2 split the grain. At even greater distances from the wellbore, branched fractures were observed more frequently (Figs 7e and f), and multiple fractures propagated in parallel over some areas, as shown in Figs 7(m) and (n). The brightness of the fluid path (i.e. induced fracture) decreased compared to the region closer to the wellbore, indicating a narrower fracture. Approximately $40 \mathrm{~mm}$ from the wellbore, the brightness further decreased, as shown in
Figs $7(\mathrm{~g})$ and $(\mathrm{h})$, and the complexity of the fractures increased. The frequency of branching further increased, and the convergence of branched fractures was also observed.

The interaction between the fracture and constituent grains resulted in extremely complex fractures or mesh-like fracture networks, as shown in Fig. 8. The organic inclusions also seemed to contribute to fracture complexity. Around the bar-like shape inclusion (A in Fig. 9a), the fractures became more complex due to branching. Additionally, penetration of the fracturing fluid along the inclusions was observed. In Figs 9(a) and (c), the many inclusions appeared black under UV light and were complexly distributed. In these areas, the fractures appeared to run through the inclusions and connect them, resulting in branched (B in Fig. 9a) or finely bending paths ( $\mathrm{C}$ in Fig. 9c). In actual production fields, organic inclusions, which likely store gas/oil resources, may behave as a weak part and result in complex fractures, contributing to the efficient production of gas/oil via hydraulic fracturing.

\section{MOMENT TENSOR ANALYSIS}

We estimated seismic moment tensors for the obtained AEs from polarities of $P$-wave first motions and their amplitudes after correcting the directivity and sensitivity depending on the coupling conditions. Details of the method of estimation/correction of $\mathrm{AE}$ sensor characteristics and moment tensor inversion are reported by Yamamoto et al. (2019).

\subsection{Calibration of AE sensor sensitivity}

We assume that a transmitter $j$ sends a pulse of amplitude $A_{0}$ to a receiver $i$, where the amplitude $A_{i j}$ recorded by receiver $i$ is given by eq. (2) (Kwiatek et al. 2014).

$A_{i j}=S_{i} I_{i} G_{i j} I_{j} S_{j} A_{0}$,

where $S_{i}$ and $S_{j}$ are the coupling coefficients of the receiver and transmitter, respectively. The term $G_{i j}$ is a Green's function between the two transducers; we assumed $G_{i j} \propto 1 / R_{i j}$, where $R_{i j}$ is the distance between the transducers, under the assumption of an isotropic homogeneous medium. In addition, $I_{i}$ and $I_{j}$ are the directivity functions of the $\mathrm{AE}$ transducers, which were assumed to follow bell-shaped curves defined by:

$I_{i}=\exp \left(-a_{r} \alpha^{b_{r}}\right), I_{j}=\exp \left(-a_{t} \beta^{b_{t}}\right)$,

where $\alpha$ and $\beta$ denote the angles between the ray path of the wave and the transducers; $a_{r}$ and $b_{r}$ are the coefficients for the receiver, while $a_{t}$ and $b_{t}$ are the coefficients for the transmitter describing the shape of the functions evaluated from a test using a semi-circular columnar Al block (see details in Yamamoto et al. 2019). Values of $a_{r}=0.53$ and $b_{r}=2.35$ for the the PICO sensor and $a_{r}=0.90$ and $b_{r}=1.47$ for the M304A sensor were obtained. In the following analysis, we assumed that $a_{r}=a_{t}$ and $b_{r}=b_{t}$ for both sensors. The curves of $I$ with those coefficients are shown in Fig. 10. In fact, eqs (2) and (3) are functions of frequency; however, we ignored the frequency dependency for simplicity.

Because the sensitivity of the AE sensor depends on the sensorspecimen coupling conditions, we evaluated the coefficients $S_{i}$ and $S_{j}$ for each experiment. After attaching the AE transducers in the configuration shown in Figs 2(b) and (c) and applying a 5-MPa load, we conducted pulse radiation tests in which the other 23 transducers recorded the test pulse of amplitude $A_{0}$ radiated from each PICO transducer. From eqs (2) and (3), the $A_{i j}$ values were represented 
(a)

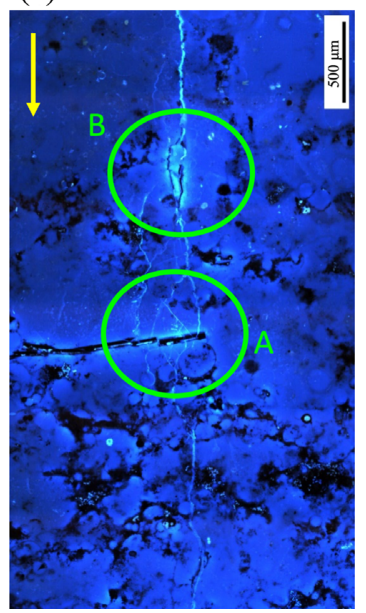

(b)

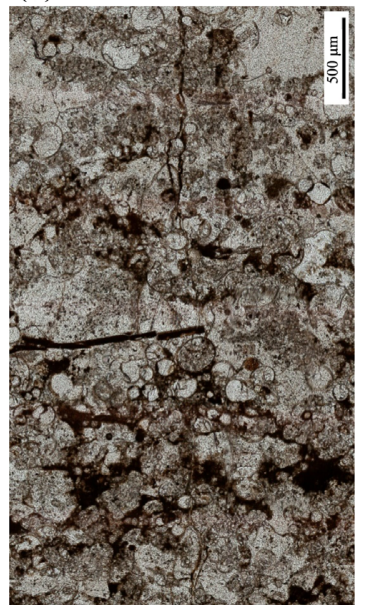

(c)

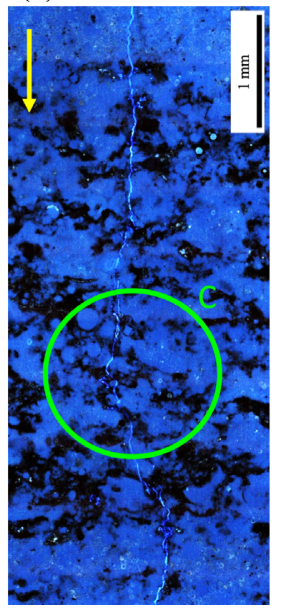

(d)

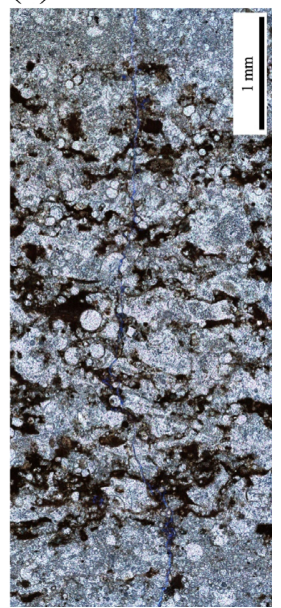

Figure 9. Examples of complex fracture patterns around inclusions, likely originating from organic substances in Eagle Ford shale blocks. (a) and (b) Branching of hydraulically induced fractures around bar-shape inclusion (thin section for $x=0.0 \mathrm{~mm}$ slice of EFS1701). (a) Under UV light, (b) crossed Nicols. (c) and (d) Complex patterns in the region where black inclusions were densely concentrated (thin section for $x=0.0 \mathrm{~mm}$ slice of EFS1701). (c) Under UV light, (d) crossed Nicols with UV light.

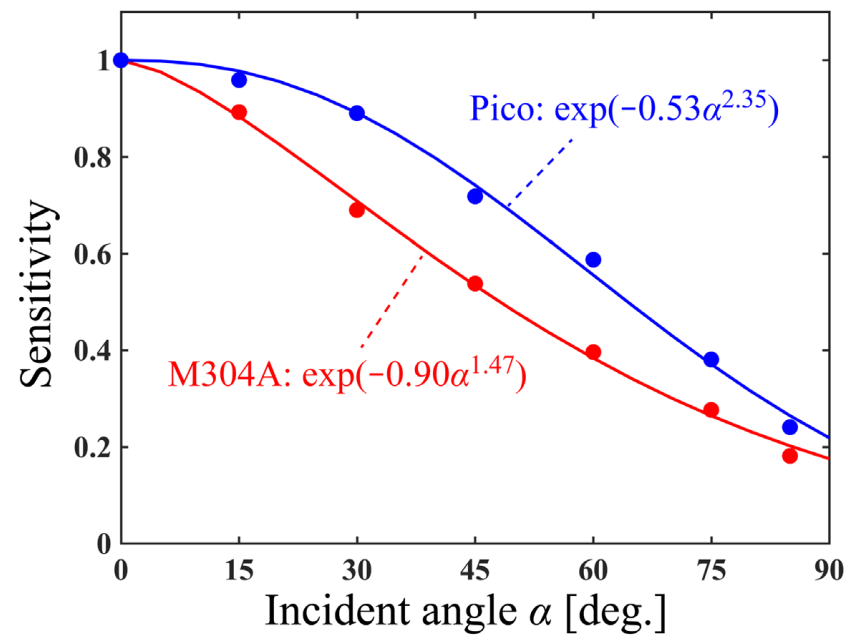

Figure 10. AE sensor directivity measured using a semi-circular columnar Al block. The data points show the maximum amplitude of $P$ wave first motions obtained for multiple tests at each angle. The lines represent the fitting results for the data.

using:

$A_{i j}=\frac{1}{R_{i j}} \exp \left(-a_{r} \alpha^{b_{r}}\right) \exp \left(-a_{t} \beta^{b_{t}}\right) S_{i} S_{j} A_{0}$.

The unknown parameters in eq. (4) are $S_{i}$, and $S_{j}$ in the case that only the relative sensitivity is required, as in the present study. We obtained 184 amplitude data for each experiment and estimated $S_{i}$ and $S_{j}$ using the Levenberg-Marquardt inversion. In the inversion process, we used 158 data sets after excluding 26 sets where the transmitter and receiver were attached to the same plane.

Figs 11(a)-(c) shows the amplitudes obtained in the pulse radiation test, where the amplitudes are plotted against the angle $\theta$, the average of incident angle $\alpha$, and projection angle $\beta$. Figs 11(d)-(f) shows the same plot after correcting the coupling coefficients $S_{i}$ and $S_{j}$ and the geometrical spreading effect $1 / R_{i j}$. In Figs $11(\mathrm{~d})-(\mathrm{f})$, the following theoretical curve was overlaid (red lines): (1) $\alpha=0^{\circ}$ and $\beta=2 \theta$; (2) $\alpha=\beta=\theta$ and (3) $\alpha=2 \theta$ and $\beta=0^{\circ}$ for the case where the M304A transducer received the pulse transmitted from a
PICO transducer. Case 1 also corresponds to that case where both the transmitter and receiver were PICO transducers. The theoretical curves corresponding to the actual tests showed values between these three theoretical curves depending on the ratio of $\alpha$ and $\beta$. The amplitudes after the correction are shown in Figs 11(e) and (f); most data lies within the area defined by the three theoretical curves, indicating that the coupling coefficients were estimated appropriately for EFS1704 and EFS1706. In contrast, the corrected amplitudes shown in Fig. 11(d) were scattered and deviated significantly from the theoretical curves, indicating that the calculated coupling coefficients were not appropriate for EFS1701. For this specimen, we observed macroscopic cracks subparallel to the $x-z$ plane on the $+y$ side of the sample. This crack likely caused significant decay or reflection of the seismic wave; these effects are not considered in eq. (4). Hence, we excluded this specimen from further analysis.

\subsection{Moment tensor inversion}

We inversely estimated full-moment tensors (i.e. six independent components) using the polarities of the $P$ wave first motions and their amplitudes after correcting the influence of the coupling coefficient and sensor directivity. The detailed analysis procedure has been published elsewhere (Yamamoto et al. 2019). For the moment tensor analysis, we chose events from the DD-relocated AE events satisfying the following criteria: (1) signal-to-noise ratio of $\geq 8$ for at least eight of the transducers. (2) $P$-wave polarities can be read from 10 or more transducers. For the obtained solutions, we estimated the variance reduction $R$ to be as follows:

$R=\left(1-\frac{\sum\left|\boldsymbol{A}-\boldsymbol{A}_{t h}\right|^{2}}{\sum|\boldsymbol{A}|^{2}}\right) \times 100$,

where $\boldsymbol{A}$ is the amplitude of the $P$ wave after the correction for coupling and incident-angle effects, and $\boldsymbol{A}_{\text {th }}$ is the theoretical amplitude. The following analysis considers solutions for $R \geq 50$. In the inversion process, we excluded data where $P$-wave polarities were unreadable, unlike the treatment of Yamamoto et al. (2019).

Fig. 12 shows source-type plots of the obtained moment tensor solutions for the experiments with samples EFS1704 and EFS1706. We used the simplified decomposition method (Vavryčuk 2015) to 

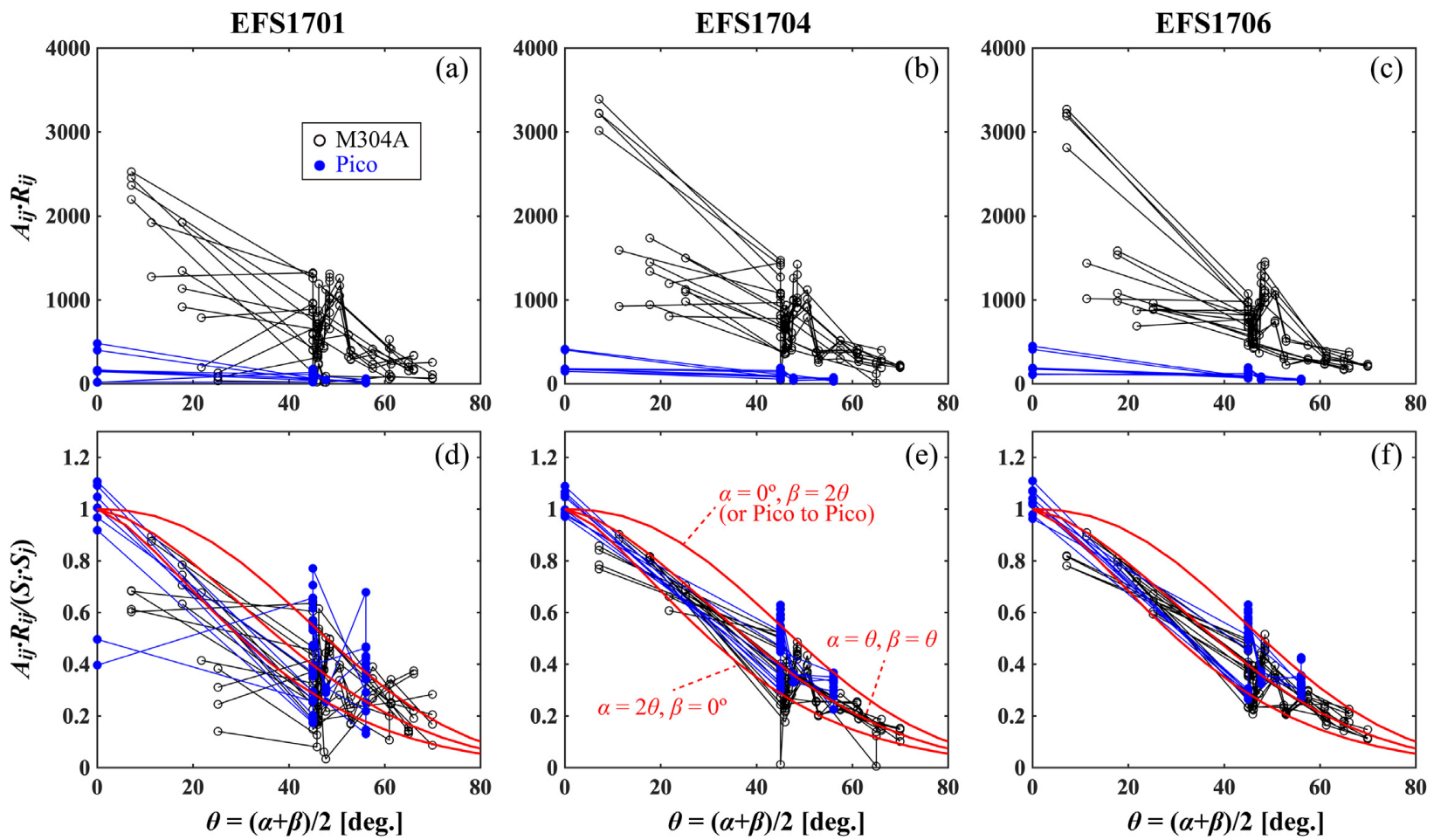

Figure 11. Results of coupling coefficient analysis. (a)-(c) Raw amplitudes recorded at each receiver in the pulse radiation test for the three samples. The records for each receiver are connected by the lines. The horizontal axis denotes the average of an incident angle $\alpha$ for a receiver and a projection angle $\beta$ for a transmitter. (d), (e) and (f) show the same plots as (a), (b) and (c), respectively, after correction of the coupling coefficients and geometrical spreading effect for the three samples. The red lines represent the theoretical directivities for three special cases.

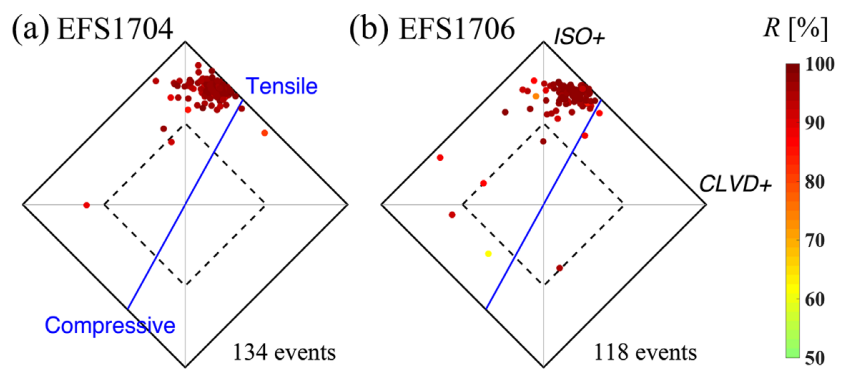

Figure 12. Source-type plot for the moment tensors obtained for samples (a) EFS1704 and (b) EFS1706. Solutions in the square area surrounded by the dashed lines correspond to events having double couple components of $\geq 50$ per cent (i.e. $|c| \leq 0.5$ ). The colours represent the variance reduction $R$ of each solution. Ideal shear-tensile events (Vavryčuk 2011) correspond to the solutions on the blue line, which are determined by the ratio of $V_{P}$ to $V_{S}$ (Vavryčuk 2015).

decompose the moment tensors to isotropic, compensated linear vector dipole (CLVD), and double-couple components. Almost all solutions were concentrated in the area corresponding to tensile or explosion events. As would be expected from the conventional theory of hydraulic fracturing (e.g. Hubbert \& Willis 1957; Yew \& Weng 2014), tensile fractures were deemed to be dominant in the present case.

We calculated the consistency coefficient $c$ for each moment tensor solution using the following equation (Vavryčuk 2011):

$c=\operatorname{sign}\left(\frac{M_{I S O}}{M_{C L V D}}\right)\left|1-\frac{M_{D C}}{100}\right|$,

where $M_{I S O}, M_{C L V D}$ and $M_{D C}$ are the percentages of each component after decomposition. Here, $c$ is a value between -1 and 1 , and a moment tensor solution is consistent with the shear-tensile model if $c \geq 0$ (Vavryčuk 2011). The value of $c$ approaches 1 when the tensile or compressive component becomes large. In the following analysis, we choose solutions with $c>0.5$, situated within the first quadrant of the source-type plot to select tensile events.

For the selected events, we calculated the fault normal direction $\boldsymbol{n}$ and the dislocation direction $\boldsymbol{v}$ using eqs (7) and (8) (Vavryčuk 2011):

$\boldsymbol{n}=\sqrt{\frac{M_{1}-M_{2}}{M_{1}-M_{3}}} \boldsymbol{e}_{1}+\sqrt{\frac{M_{3}-M_{2}}{M_{3}-M_{1}}} \boldsymbol{e}_{3}$,

$\boldsymbol{v}=\sqrt{\frac{M_{1}-M_{2}}{M_{1}-M_{3}}} \boldsymbol{e}_{1}-\sqrt{\frac{M_{3}-M_{2}}{M_{3}-M_{1}}} \boldsymbol{e}_{3}$.

Here, $M_{1}, M_{2}$, and $M_{3}$ are the maximum, intermediate, and minimum eigenvalues of a moment tensor, respectively. Eigenvectors $\boldsymbol{e}_{\boldsymbol{1}}$ and $\boldsymbol{e}_{3}$ correspond to $M_{1}$ and $M_{3}$, respectively. Although $\boldsymbol{n}$ and $\boldsymbol{v}$ are complementary solutions and cannot be determined uniquely (i.e. two candidates of a source model exist for a pair of $\boldsymbol{n}$ and $\boldsymbol{v}$ ), this uncertainty is not problematic in the present case because $\boldsymbol{n}$ and $\boldsymbol{v}$ have similar directions for events with a large $c$. Fig. 13 shows the $y-z$ projections of the $\boldsymbol{n}$ and $\boldsymbol{v}$ directions of the selected events and their polar coordinate histograms of the dip angles. Most $\boldsymbol{n}$ and $\boldsymbol{v}$ were subparallel to the horizontal $(x-y)$ plane, indicating the occurrence of tensile events for which the crack plane is parallel to the $x-z$ plane. As is explained by the conventional theory of hydraulic fracturing (Hubbert \& Willis 1957), the theoretical solution for the stress field around a pressurized hole would lead to the generation of such events near the wellbore. Stress concentration around the 
EFS1704 (123 events)

(a)

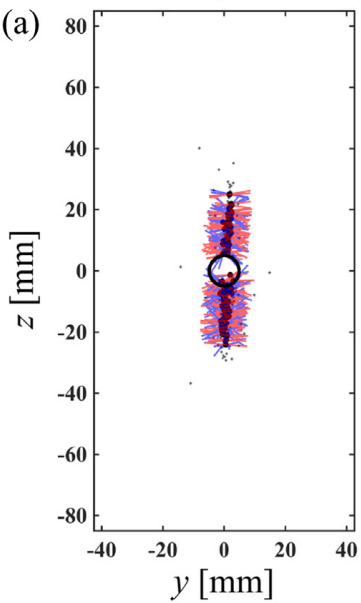

(c)

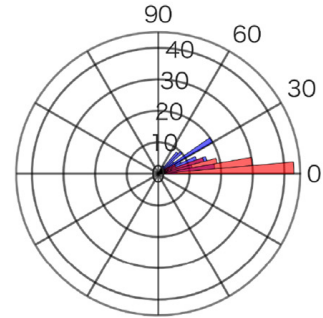

EFS1706 (106 events)

(b)

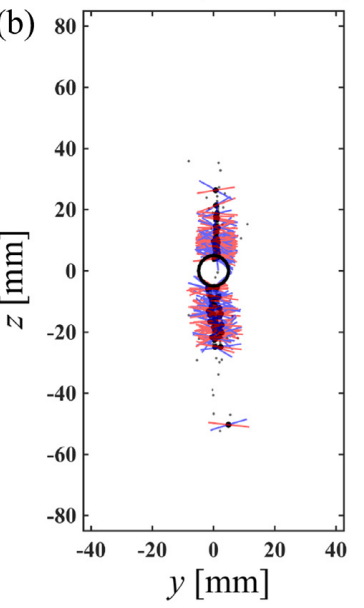

(d)

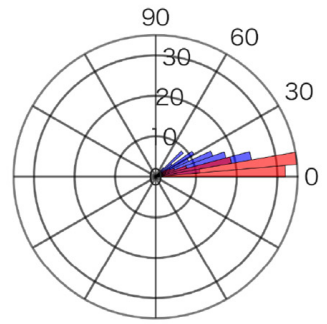

Figure 13. (a, b) $y-z$ projections of the fault normal direction $\boldsymbol{n}$ and dislocation direction $\boldsymbol{v}$ of EFS1704 and EFS1706, respectively. $\boldsymbol{n}$ and $\boldsymbol{v}$ are plotted for the moment tensors that have $c>0.5$ and are situated in the first quadrant of the source-type plot (i.e. tensile-dominant events). The number of events is shown above each panel. For each pair of $\boldsymbol{n}$ and $\boldsymbol{v}$, the vector with a higher dip angle is shown in blue and another in red. Hypocentres relocated by the double-difference method, including events whose moment tensors were not determined, are overlaid (grey dots). (c, d) Polar coordinate histogram of dip angles of $\boldsymbol{n}$ and $\boldsymbol{v}$ for EFS1704 and EFS1706, respectively.

crack tip of the induced tensile fracture also explains events having similar focal mechanisms far from the wellbore.

\section{DISCUSSION}

\subsection{Interpretation of fracture propagation process}

In the present experiments for outcrop samples of Eagle Ford shale, the generation of simple bi-wing fractures extending from the wellbore along the maximum compression axis was confirmed from an analysis of the cut sections. Although the fractures reached close to the edge of the specimen, AE hypocentres were determined only within 20-30 mm of the wellbore. AE activity began several seconds before the peak pressure was observed, but was not detected during and after breakdown. The active region of the AE events migrated towards the outside of the sample with increasing fluid pressure, and the migration speed quickly increased; this is direct evidence for the increase in the stress intensity factor at the crack tip. In this phase, the pressurized fluid likely reaches the crack tip at a rate sufficient to continuously increase the stress level at the crack tip due to the limited fracture propagation speed (Zoback \& Pollard 1978). The observation of intragranular cracks and the AE magnitude increasing at an increasing rate were interpreted as evidence of an increasing stress concentration or high-stress region at the crack tip developing during fracturing.
Although AE events were not observed after the peak pressure, large-amplitude seismic waves were recorded during breakdown. We propose that the fracture propagated dynamically in this phase owing to cracks larger than the critical crack length (Griffith 1921; Irwin 1957). The width of the observed fractures in the region without $\mathrm{AE}$ events decreased with distance from the wellbore, indicating a small amount of penetrated fluid. We concluded that the supply of fluid to the crack tip could not catch up with the rapid propagation of the fracture. Such transition from the fluid pressure-driven phase to the fluid diffusion phase due to rapid fracture propagation was also reported in previous studies (Li et al. 2016). This likely causes the decrease in the stress intensity factor during the dynamic phase, resulting in a narrower fracture, and may also result in termination of the fracture.

\subsection{Interpretation of dominant focal mechanisms}

In the present experiments, almost all moment tensor solutions of the observed $\mathrm{AE}$ events indicated the generation of tensile cracks along the maximum compression axis, which is consistent with the conventional hydraulic fracturing theory. However, the extreme dominance of such tensile events was rarely observed. To the best of our knowledge, such a case has not been published for laboratory/in situ experiments or in the production field. Shear seismic events are often dominant in actual production fields (Maxwell \& Cipolla 2011; Š́lený et al. 2014; Staněk \& Eisner 2017) and in situ experiments (Ishida et al. 2019). Previous studies of hydraulic fracturing in the laboratory also showed that significant proportions of induced seismic events were shear-type for rocks such as shale (Bennour et al. 2015; Zhang et al. 2019), sandstone (Stoeckhert et al. 2015; Rodriguez et al. 2017), slate (Stoeckhert et al. 2015) and granite (Ishida et al. 2016; Yamamoto et al. 2019), even for experiments adopting loading conditions and sample sizes similar to those used in the present study (Yamamoto et al. 2019). Although moment tensor analysis for laboratory-observed AE events is difficult because of the complicated characteristics of AE sensors, such studies also reported that a significant proportion of AE events were shear-type (Rodriguez et al. 2017; Yamamoto et al. 2019). In addition, previous studies based on polarity analysis of $P$ wave first motions also showed the existence of dilatational polarities in a significant proportion (Stoeckhert et al. 2015; Zhang et al. 2019). Although event-type classification based only on polarities could misidentify CLVD-dominant events as shear-type events, almost all events in this study showed compressional polarities for all sensors, which has not been reported in previous studies.

The differences in the dominant mechanism of the AE/MS events induced by hydraulic fracturing probably depend on how the fracturing fluid interacts with the pre-existing cracks. This should be influenced by the directions of the pre-existing cracks, their density, the permeability of the medium, viscosity of the fracturing fluid, and stress state. For example, Yamamoto et al. (2019) showed that the dominant mode of AE events depends on the direction of the pre-existing cracks during laboratory-scale hydraulic fracturing experiments with granite samples. In this study, interaction between the fracturing fluid and pre-existing cracks may be limited owing to the very-low-permeable rock with few microscopic pre-existing cracks, resulting in the extreme dominance of tensile fracture. The lack of AE activity after breakdown, which is abundant for granite (Naoi et al. 2018), and the fact that the AE events occurred only around the crack tip was evidence of the lack of fluid penetration into such pre-existing cracks. Our results revealed that the classical 
theory could explain the mode of induced seismic events during the hydraulic fracturing of very tight rock, although it is significantly affected by the pre-existing crack distribution, which likely controls the microseismic activities observed in actual production.

\section{CONCLUSIONS}

We performed hydraulic fracturing experiments in the laboratory using shale samples from the Eagle Ford outcrop, which is the main geological formation exploited for shale gas/oil production in the USA. The formation of simple, planar, bi-wing fractures was observed by direct observation using a fluorescent thermosetting acrylic resin and AE measurement. AE measurements revealed the fracture growing process from the quasi-static to dynamic propagation. The direct observation revealed a change in the fracture morphology during the growing process, and interactions between induced fractures and constituent grains/inclusions. The observed features are very different from the results previously reported for the other type rocks, and it was confirmed that the fracture growth process and accompanying seismic activities were highly dependent on the rock type. Especially, moment tensor analysis revealed the extreme domination of tensile AE events, much different from the previous studies. This is likely due to the use of an extremely tight rock and indicates that the pre-existing fractures strongly influence the mode of seismic events induced by hydraulic fracturing.

\section{ACKNOWLEDGEMENTS}

We thank the two reviewers for their constructive comments. This work was supported financially by the Japan Oil, Gas and Metals National Corporation (JOGMEC) and JSPS KAKENHI Grant Number 16H04614.

\section{REFER ENCES}

Akai, T., Yano, S., Kurosawa, I., Chen, Y. \& Ishida, T., 2015. Consideration on shape of hydraulic fracture based on laboratory experiment, in $\mathrm{Abu}$ Dhabi International Petroleum Exhibition and Conference, 9-12 November, Abu Dhabi, UAE, SPE-177673-MS, doi: 10.2118/177673-MS.

Allen, R.V., 1978. Automatic earthquake recognition and timing from single traces, Bull. seism. Soc. Am., 68, 1521-1532.

Anovitz, L.M. et al., 2015. Effects of maturation on multiscale (nanometer to millimeter) porosity in the Eagle Ford Shale, Interpretation, 3, SU59SU70, doi: 10.1190/INT-2014-0280.1.

Bennour, Z., Ishida, T., Nagaya, Y., Chen, Y., Nara, Y., Chen, Q., Sekine, K. \& Nagano, Y., 2015. Crack extension in hydraulic fracturing of shale cores using viscous oil, water, and liquid carbon dioxide, Rock Mech. Rock Eng., 48, 1463-1473.

Chen, Y., Naoi, M., Tomonaga, Y., Akai, T., Tanaka, H., Takagi, S. \& Ishida, T., 2018. Method for visualizing fractures induced by laboratory-based hydraulic fracturing and its application to shale samples, Energies, 11, 1976, doi:10.3390/en11081976.

Cho, Y., Eker, E., Uzun, I., Yin, X. \& Kazemi, H., 2016. Rock characterization in unconventional reservoirs: a comparative study of Bakken, Eagle Ford, and Niobrara formations, in SPE Low Perm Symposium, Denver, CO, USA, SPE-180239-MS, doi.org/10.2118/180239-MS.

Cornet, F.H., 2016. Seismic and aseismic motions generated by fluid injections, Geomech. Ener. Environ., 5, 42-54.

Griffith, A., 1921. The phenomena of rupture and flow in solids, Phil. Trans. R. Soc. Lond, 221A, 163-198.

Hallo, M., Oprsal, I., Eisner, L. \& Ali, M.Y., 2014. Prediction of magnitude of the largest potentially induced seismic event, J. Seismol., 18, 421-431.

Hubbert, M.K. \& Wills, D.G., 1957. Mechanics of hydraulic fracturing, Trans. Soc. Petrol. Eng. AIME, 210, 153-168.
Irwin, G. R., 1957. Analysis of Stresses and strains near the end of a crack transversing a plate, Trans. ASME, J. Appl. Mech., 24, 361-364.

Ishida, T. et al., 2016. Features of $\mathrm{CO}_{2}$ fracturing deduced from acoustic emission and microscopy in laboratory experiments, J. geophys. Res., 121, 8080-8098.

Ishida, T., Fujito, W., Yamashita, H., Naoi, M., Fuji, H., Suzuki, K. \& Matsui, H., 2019. Crack expansion and fracturing mode of hydraulic refracturing from acoustic emission monitoring in a small-scale field experiment, Rock Mech. Rock Eng., 52, 543-553.

Kwiatek, G., Charalampidou, E., Dresen, G. \& Stanchits, S., 2014. An improved method for seismic moment tensor inversion of acoustic emissions through assessment of sensor coupling and sensitivity to incidence angle, Int. J. Rock Mech. Min. Sci., 65, 153-161.

Li, X., Lei, X. \& Li, Q., 2016. Injection-induced fracturing process in a tight sandstone under different saturation conditions, Environ. Earth Sci., 75, 1466, doi:10.1007/s12665-016-6265-2.

Maxwell, S.C. \& Cipolla, C., 2011. What does microseismicity tell us about hydraulic fracturing?, in SPE Annual Technical Conference and Exhibition, Denver, CO, SPE146932, doi: 10.2118/146932-MS.

Maxwell, S.C., 2014. Microseismic Imaging of Hydraulic Fracturing: Improved Engineering of Unconventional Shale Reservoirs, SEG Distinguished Instructor Series, 17, doi:10.1190/1.9781560803164.

McGarr, A. \& Barbour, A.J., 2018. Injection-induced moment release can also be aseismic. Geophysi. Res. Lett., 45, 5344-5351.

Naoi, M. et al., 2018. Monitoring hydraulically-induced fractures in the laboratory using acoustic emissions and the fluorescent method, Int. J. Rock Mech. Min. Sci., 104, 53-63.

Rodriguez, I.V., Stanchits, S. \& Burghardt, J., 2017. Data-driven, in-situ, relative sensor calibration based on waveform fitting moment tensor inversion. Rock Mech. Rock Eng., 50, 891-911.

Romero, A.A.M., Nguyen, T. \& Philp, R.P., 2018. Organic geochemistry of the Eagle Ford Group in Texas, AAPG Bull., 102, 1379-1412.

Rothman, R.L., Greenfield, R.J. \& Hardy, H.R., 1974. Errors in hypocenter location due to velocity anisotropy, Bull. seism. Soc. Am., 64, 1993-1996.

Š́lený, J., Jechumtálová, Z. \& Dorbath, C., 2014. Small scale earthquake mechanisms induced by fluid injection at the enhanced geothermal system reservoir Soultz (Alsace) in 2003 using alternative source models, Pure appl. Geophys., 171, 2783-2804.

Staněk, F. \& Eisner, L., 2017. Seismicity induced by hydraulic fracturing in shales: a bedding plane slip model, J. geophys. Res., 122, 7912-7926.

Stanchits, S., Surdi, A., Gathogo, P., Edelman, E. \& Suarez-Rivera, R., 2014. Onset of hydraulic fracture initiation monitored by acoustic emission and volumetric deformation measurements. Rock Mech. Rock Eng., 47, 15211532 .

Stoeckhert, F., Molenda, M., Brenne, S. \& Alber, M., 2015. Fracture propagation in sandstone and slate-laboratory experiments, acoustic emissions and fracture mechanics, J. Rock Mech. Geotech. Eng., 7, 237-249.

Takanami, T. \& Kitagawa, G., 1988. A new efficient procedure for the estimation of onset times of seismic waves, J. Phys. Earth, 36, 267-290.

Waldhauser, F. \& Ellsworth, W.L., 2000. A double difference earthquake location algorithm: method and application to the Northern Hayward fault, California, Bull. seism. Soc. Am., 90, 1353-1368.

Vavryčuk, V., 2011. Tensile earthquakes: theory, modeling and inversion, $J$. geophys. Res., 116, doi:10.1029/2011JB008770.

Vavryčuk, V., 2015. Moment tensor decomposition revisited, J. Seismol., 19, 231-252.

Yamamoto, K. et al., 2019. Moment tensor analysis of acoustic emissions induced by laboratory-based hydraulic fracturing in granite, Geophys. J. Int., 216, 1507-1516.

Yew, C.H. \& Weng, X., 2014. Mechanics of Hydraulic Fracturing, Gulf Professional Publishing.

Zoback, M. D. \& Pollard, D. D., 1978. Hydraulic fracture propagation and the interpretation of pressure-time records for in-situ stress determinations, in Proceedings of the 19th US Rock Mech. Symp., Mackay School of Mines, Reno, Nevada, pp. 14-22.

Zhang, B., Tian, X., Ji, B., Zhao, J., Zhu, Z. \& Yin, S., 2019. Study on microseismic mechanism of hydro-fracture propagation in shale, J. Petrol. Sci. Eng., 178, 711-722. 